\title{
Geologia
}

\section{Utilização de Elipsoide de Anisotropia Variográfica como Indicador Cinemático em Maciços Rochosos Fragmentados por Falhas - 0 Exemplo do Depósito de Asbestos Crisotila Cana Brava (Minaçu, GO)}

\author{
Use of the Ellipsoid of Variographic Anisotropy as a Kinematic Indicator in Rock \\ Massifs Fractured by Faults - the Example of the Cana Brava Chrysotile Asbestos \\ Deposit ( $M$ inaçu, G O)
}

\author{
Carlos Eduardo dos Santos (hidrogeo@gmail.com) e João Carlos Biondi (jcbiondi@ ufpr.br) \\ Departamento de Geologia - UFPR \\ Caixa Postal 19.001, CEP 81531-980, Curitiba, PR, BR
}

Recebido em 19 de abril de 2011; aceito em 19 de setembro de 2011

\begin{abstract}
RESUMO
Os parâmetros de um variograma dependem da direção na qual é calculado, assim como o elipsoide de anisotropia variográfica, cujos eixos indicam as direções de maior, média e menor continuidade da variável utilizada para calcular o variograma. Essa característica torna o elipsoide um indicador cinemático, visto que os elipsoides de anisotropia de blocos de um mesmo maciço rochoso ou corpo mineralizado serão rotados se os blocos o forem. O corpo mineralizado em crisotila do depósito Cana Brava é composto por 13 blocos, individualizados por falhas. Comparando os elipsoides de anisotropia variográfica da variável teor de crisotila desses 13 blocos, foi possível perceber que, apesar de deslocados uns em relação aos outros, na maioria das vezes o deslocamento ocorreu sem rotação. Isso permitiu unir blocos e usar apenas seis elipsoides, e seus respectivos variogramas, para estimar a quantidade de crisotila contida no depósito.
\end{abstract}

Palavras-chave: Elipsoide de anisotropia; Indicador cinemático; Depósito de crisotila; Cana Brava.

\begin{abstract}
The parameters of a variogram depend on which direction it is calculated, such as the ellipsoid of variographic anisotropy, whose axes indicate the directions of higher, medium and lower continuity of the variable used to calculate the variogram. Consequently, the ellipsoid can be used as a kinematic indicator, since the anisotropy ellipsoids of blocks of the same rock massif or mineralized body will be rotated if the blocks are also rotated. The chrysotile ore body of the Cana Brava Asbestos deposit is composed of 13 blocks separated by faults. Comparing the ellipsoids of variographic anisotropy of the variable amount of chrysotile in these 13 blocks, it was observed that, although they are displaced in relation to each other, in most cases this displacement was not caused by rotation. As a result, it was possible to group some blocks together and use only six ellipsoids and their respective variograms to estimate the amount of chrysotile in the deposit.
\end{abstract}

Keywords: Ellipsoid of anisotropy; Kinematic indicator; Chrysotile deposit; Cana Brava. 


\section{INTRODUÇÃO}

Os termos asbesto ou amianto são designações comerciais, genéricas, de variedades fibrosas de seis minerais metamórficos: crisotila, crocidolita, amosita, antofilita, tremolita e actinolita. Deste grupo, a crisotila é uma serpentina fibrosa e os demais minerais são anfibólios aciculares. Cristais de crisotila apresentam grande flexibilidade e resistências tênsil, química, térmica e elétrica muito elevadas. Devido a tais propriedades, é usado como agregador e em tecelagem, sendo amplamente empregado na indústria de fibrocimento, papéis e papelões, produtos de vedação, produtos têxteis, produtos de fricção, isolantes térmicos, filtros e revestimento de piso.

A mina Cana Brava situa-se no extremo norte do Estado de Goiás, na extremidade sudeste da Serra Cana Brava, no Município de Minaçu. Geograficamente, está na interseção das coordenadas $13^{\circ} 14^{\prime}$ de latitude sul e $48^{\circ} 14^{\prime}$ ' longitude oeste. Descoberta em 1960 e lavrada desde 1966, Cana Brava, então com $150 \mathrm{Mt}$ de minério com teor médio de 3,5\% em peso de crisotila, é o maior depósito de asbestos crisotila da América do Sul.

\section{GEOESTATÍSTICA}

Em geoestatística, a maioria das informações relacionadas a um ponto não amostrado $\mathrm{Z}\left(\mathrm{x}_{\mathrm{o}}\right)$ é estimada a partir das realizações de pontos amostrados em locações vizinhas, $\{\mathrm{Z}(\mathrm{X} \alpha), \alpha=1 \ldots . \mathrm{n}\}$ seja sobre um mesmo atributo $\mathrm{Z}$ ou sobre um atributo correlacionável f[Y $(\mathrm{z})]$. O conceito probabilístico de função aleatória permite a modelagem do grau de correlação ou dependência entre qualquer numero de variáveis $\mathrm{Z}(\mathrm{x}),\{\mathrm{Z}(\mathrm{X} \alpha), \alpha=1, \ldots \mathrm{n}\}$. Qualquer valor de $\mathrm{Z}(\mathrm{x})$ correlaciona-se a outros valores $\mathrm{Z}(\mathrm{x}+\mathrm{h})$ que estiverem dentro de um raio " $h$ " a partir de x. Esta correlação, ou a influência de um valor em outro, aumenta conforme $\mathrm{Z}(\mathrm{x}+\mathrm{h})$ aproxima-se de $\mathrm{Z}(\mathrm{x})$.

A função variograma é a medida, usada em geoestatística, do grau de dependência espacial entre duas amostras. A função semivariograma entre dois pontos depende da distância entre eles, implicando em valores da função semivariograma menores para distâncias menores e maiores para distâncias maiores. A partir de certa distância, denominada alcance ou amplitude, a semivariância espacial não mais aumentará com a distância e se estabilizará em um valor máximo denominado sill ou patamar. Amostras separadas por distâncias iguais ou menores que aquela quando é alcançada a semivariância espacial máxima podem ser correlacionadas. Os alcances maior, médio e menor dos variogramas calculados para uma dada variável permitem construir o elipsoide de anisotropia dessa variável. Esse elipsoide é uma característica única do objeto geológico que contém a variável utilizada para calculá-lo, e pode ser utilizado para comparar esse objeto a outros objetos de uma mesma unidade geológica.

\section{Variograma e anisotropia variográfica}

O gráfico da variação das semivariâncias espaciais em função da distância a um ponto é chamado de semivariograma, a ferramenta básica da geoestatística. A função semivariograma, $\gamma(\mathrm{h})$, é definida como a soma do quadrado da diferença entre as realizações $\mathrm{Z}(\mathrm{x})$ de pontos no espaço separados por uma distancia $h$, dividido por duas vezes o número de pares de amostras $Z(x)$ e $Z(x+h)$, conforme a equação:

$$
\gamma(\mathrm{h})=\frac{1}{2 \mathrm{~N}} \sum_{1=1}^{\mathrm{n}}\left[\mathrm{Z}\left(\mathrm{x}_{\mathrm{i}}\right)-\mathrm{Z}\left(\mathrm{x}_{\mathrm{i}}+\mathrm{h}\right)\right]^{2}
$$

onde: $\gamma(\mathrm{h})$ é a função semivariograma; $\mathrm{N}$ é o numero de pares de pontos separados por uma distancia $\mathrm{h} ; \mathrm{Z}\left(\mathrm{x}_{\mathrm{i}}\right)$ é a realização da variável regionalizada no ponto $x_{i}$ e $Z\left(x_{i}+h\right)$ é a realização no ponto $\left(x_{i}+h\right)$. $O$ variograma é uma função semivetorial, dado que $2 \gamma(\mathrm{h})$ varia conforme a direção na qual é calculado.

A interpretação do variograma permite obter os parâmetros $\mathrm{a}=$ amplitude, $\mathrm{C}_{0}=$ efeito de pepita e $\mathrm{C}=$ patamar, que descrevem o comportamento espacial das variáveis regionalizadas, conforme ilustrado na Figura 1. A amplitude do variograma é o parâmetro mais importante, porque quantifica a distância máxima até a qual duas amostras podem ser correlacionadas, ou seja, é o parâmetro que define a continuidade no espaço (= distância de influência) de uma dada realização da amostra (teor, densidade etc.), na direção na qual o variograma foi calculado.

Sendo uma função direcional, a amplitude ou alcance variográfico apresenta, em cada domínio geológico homogêneo, direções com valores máximo, médio e mínimo, que podem ser determinados quando se calcula o variograma em todas as direções. Quando, fazendo uso da ferramenta "mapa de variogramas", que permite calcular variogramas simultaneamente em até 36 direções, estes valores das amplitudes variográficas são determinados, eles podem ser adotados como os três eixos de um elipsoide, denominado elipsoide de anisotropia variográfica (conforme definição de "elipsoide de anisotropia"). As dimensões dos raios desse elipsoide correspondem, nas suas respectivas direções, às distâncias máximas que duas amostras se correlacionam dentro do espaço no qual os variogramas foram calculados. No caso de um corpo geológico isótropo, homogêneo em todas as direções, os três eixos de anisotropia seriam iguais, e ao invés de um elipsoide ter-se-ia uma esfera. Qualquer outra situação caracteriza uma anisotropia da variável utilizada no cálculo dos variogramas. 


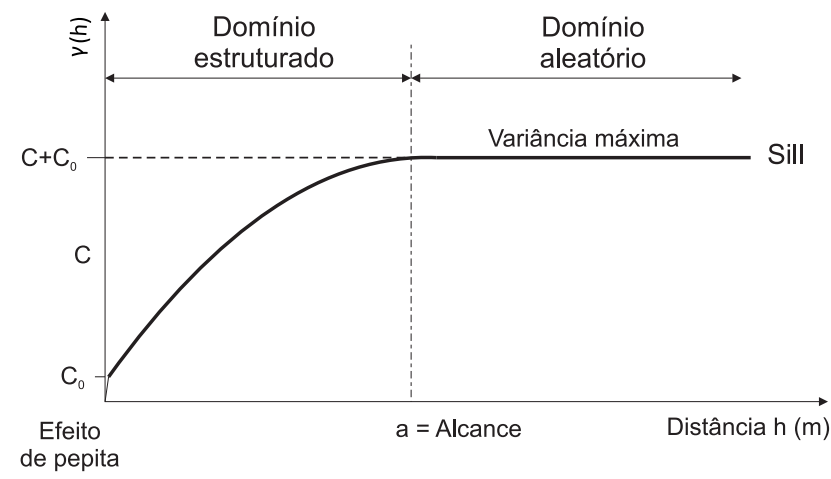

Figura 1. Imagem de um semivariograma e seus parâmetros: a (amplitude ou alcance), C (variância), C (efeito de pepita) e sill ou patamar $\left(=\mathrm{C}+\mathrm{C}_{0}\right)$.

\section{Uso do elipsoide de anisotropia como ferramenta estrutural para estimar a quantidade de metal ou mineral contida em um corpo mineralizado}

Caso se opte por estimar a quantidade de metal contido em um corpo de minério com geoestatística (cubagem geoestatística), a primeira etapa do processo é determinar a geometria do corpo mineralizado, ou modelo geométrico. Em seguida, o objeto correspondente ao modelo geométrico deve ser separado em blocos homogêneos, que serão cubados individualmente. Os limites de cada bloco homogêneo são descontinuidades observadas durante o mapeamento do depósito mineral, realizado antes do início dos procedimentos de cubagem. Na maioria das vezes são falhas ou fraturas que seccionaram o corpo mineralizado principal, embora outras estruturas possam exercer essa função, tais como discordâncias ou descontinuidades naturais ocorridas durante a formação do corpo mineralizado, entre outras.

Habitualmente considera-se, "a priori”, que os sub-blocos foram deslocados e rotados, motivos pelos quais os atributos estimados com geoestatística (teor, porosidade, densidade p.ex.) são calculados em cada bloco separadamente. $\mathrm{Na}$ realidade, a estimativa deve ser feita individualmente somente se os elipsoides de anisotropia dos blocos tiverem eixos com dimensões e orientações diferentes. Blocos que foram deslocados das suas posições originais, mas não foram rotados, terão elipsoides de anisotropia com eixos iguais e com as mesmas orientações e suas realizações poderão ser calculadas como se fossem de um objeto único, embora ocupando posições espaciais distintas. Os elipsoides de anisotropia podem, portanto, ser usados como indicadores cinemáticos de blocos, embora não quantifiquem os deslocamentos (Santos, 2011). O mesmo procedimento pode ser adotado em qualquer outro tipo de estudo estrutural, desde que, em cada bloco, se disponha de uma variável com a qual se possa calcular variogramas em todas as direções.

A Figura 2A apresenta, esquematicamente, um corpo mineralizado homogêneo e o elipsoide de anisotropia de um de seus atributos. $\mathrm{O}$ valor desse atributo pode ser estimado com geoestatística em qualquer ponto do corpo mineralizado, desde que se conheça o variograma com maior alcance do atributo em questão e o elipsoide de anisotropia do atributo no corpo mineralizado. Caso o corpo mineralizado seja segmentado e os sub-blocos resultantes sejam deslocados sem que ocorra rotação (Figura 2B), o variograma e o elipsoide de anisotropia, válidos para fazer estimativas dentro do corpo mineralizado original, poderão ser usados para fazê-lo nos sub-blocos resultantes da segmentação. Ou seja, na prática, se os elipsoides de anisotropia dos dois sub-blocos forem iguais, isso será uma indicação de que houve deslocamento dos sub-blocos, mas não houve rotação. Caso tenha havido deslocamento e rotação (Figura 2C), os elipsoides de anisotropia de cada sub-bloco terão eixos com as mesmas dimensões, mas com orientações diferentes. Nesse caso, as estimativas de pontos não amostrados de cada sub-bloco terão que ser feitas com variogramas, elipsoides de anisotropia e krigagens específicos para cada sub-bloco. Na prática, elipsoides diferentes indicam que houve deslocamento e rotação dos sub-blocos. Caso os elipsoides de anisotropia dos sub-blocos tenham eixos e orientações diferentes, ou os sub-blocos não pertencem ao mesmo corpo de minério ou o atributo (teor, densidade etc.) foi alterado simultaneamente ou após o deslocamento dos sub-blocos.

\section{ESTUDO DE CASO - O DEPÓSITO CANA BRAVA, DE ASBESTOS CRISOTILA (MINAÇÚ, GO, BRASIL)}

\section{Geologia regional}

Cana Brava é um complexo máfico-ultramáfico que integra, junto com os complexos de Niquelândia e Barro Alto, um cinturão descontínuo, com cerca de $350 \mathrm{~km}$ de extensão, no noroeste do Estado de Goiás e sudoeste de Tocantins, situado na faixa dobrada Brasília, do Neoproterozoico. É limitado a leste por uma zona milonítica que mergulha para oeste, e a oeste pelo topo da sequência vulcano-sedimentar bimodal Palmeirópolis, associada a intrusões graníticas, anortositos, gabros e leucogabros. O complexo foi intensamente deformado e metamorfisado em grau alto, o que modificou parcialmente a estratigrafia original, embora algumas estruturas e a textura ígnea originais tenham sido relativamente bem preservadas. 
A

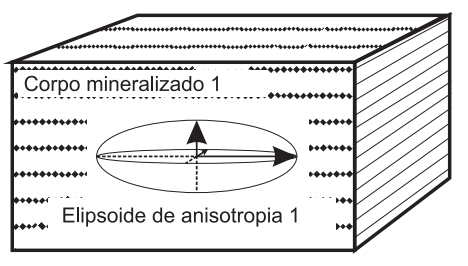

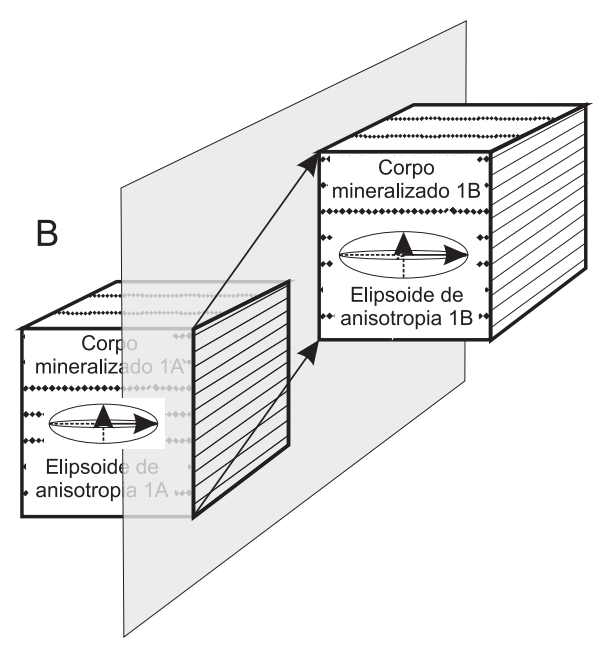

Figura 2. A. Corpo mineralizado e o elipsoide de anisotropia variográfica de um atributo qualquer do minério. B. Dois segmentos do corpo mineralizado que foram deslocados por uma falha, mas não rotados. O s elipsoides de anisotropia serão iguais nos dois sub-blocos. C. Dois segmentos deslocados e rotados, caso em que os elipsoides de anisotropia serão diferentes ou terão orientações distintas nos dois sub-blocos.

Estudos feitos em Niquelândia, Barro Alto e Cana Brava (Correia et al., 1997; Ferreira Filho et al., 1994, 1998, 2010; Ferreira Filho e Pimentel, 2000), sugeriram que os complexos seriam compostos por dois sistemas magmáticos petrologicamente distintos. Os dados isotópicos e geocronológicos mais recentes (Pimentel et al., 2003; Ferreira Filho et al., 2010) indicam que as séries superior e inferior (Figura 3) derivaram de magmas de origem distintas e, provavelmente, alojaram-se na litosfera em situações tectônica também distintas. Combinados com novas interpretações sobre a evolução da faixa Brasília, o modelo tectônico proposto por Pimentel et al. (2003) e Ferreira Filho et al. (2010) envolve quatro etapas:

1. Entre 1,30 e 1,25 Ga - Formação de um rift continental, possivelmente associado a um oceano estreito, que possibilitou a sedimentação e o vulcanismo da sequência Palmeirópolis, a oeste de Cana Brava, e seus equivalentes plutônicos. Na Figura 3, os metagabros e anfibolitos correspondem a parte vulcânica e os dioritos, noritos e gnaisses do Complexo Serra dos Borges são o equivalente plutônico da Sequência Plameirópolis.

2. Há $0,78 \mathrm{Ga}$ - Abertura de outro rift continental no qual se alojou o Complexo Estratificado de Niquelândia, Barro Alto e Cana Brava (Ferreira Filho et al., 2010) As Zonas Máficas Inferior e Superior e a Zona Ultramáfica, atualmente situadas na base do Complexo (Figura 3), alojaram-se durante esse segundo episódio plutônico.
3. Há $0,76 \mathrm{Ga}$ - Toda a região foi metamorfisada em grau alto, da fácies granulito, a leste, até a fácies anfibolito a oeste.

4. Há $0,63 \mathrm{Ga}$ - Metamorfismo regional provavelmente associado ao fechamento do oceano e à colisão entre os páleo-continentes São Francisco e Amazonas.

\section{Geologia do Complexo Cana Brava}

\section{Estratigrafia}

A parte estratificada do Complexo Máfico-Ultramáfico Cana Brava é uma intrusão composta por três zonas, denominadas Zona Máfica Superior, Zona Máfica Inferior e Zona Ultramáfica. A subdivisão estratigráfica proposta (Figura 3) considera que a sequência de cobertura, em Cana Brava denominada Sequência Vulcano-Sedimentar Palmeirópolis, contém as rochas vulcânicas e as plutônicas do Complexo Serra dos Borges. Essas plutônicas são noritos, quartzo-noritos e gnaisses básicos, recobertos por anfibolitos, correspondentes metamórficos das vulcânicas básicas.

Embora espacialmente as Zonas Máficas Inferior e Superior e a Zona Ultramáfica situem-se abaixo da Sequência Palmeirópolis e do Complexo Serra dos Borges, essas zonsa são compostas por rochas mais jovens, cristalizadas na segunda fase de rift, há cerca de $0,78 \mathrm{Ga}$. São formadas por olivina-melagabronorito e por uma sequência homogênea de metagabronorito. 


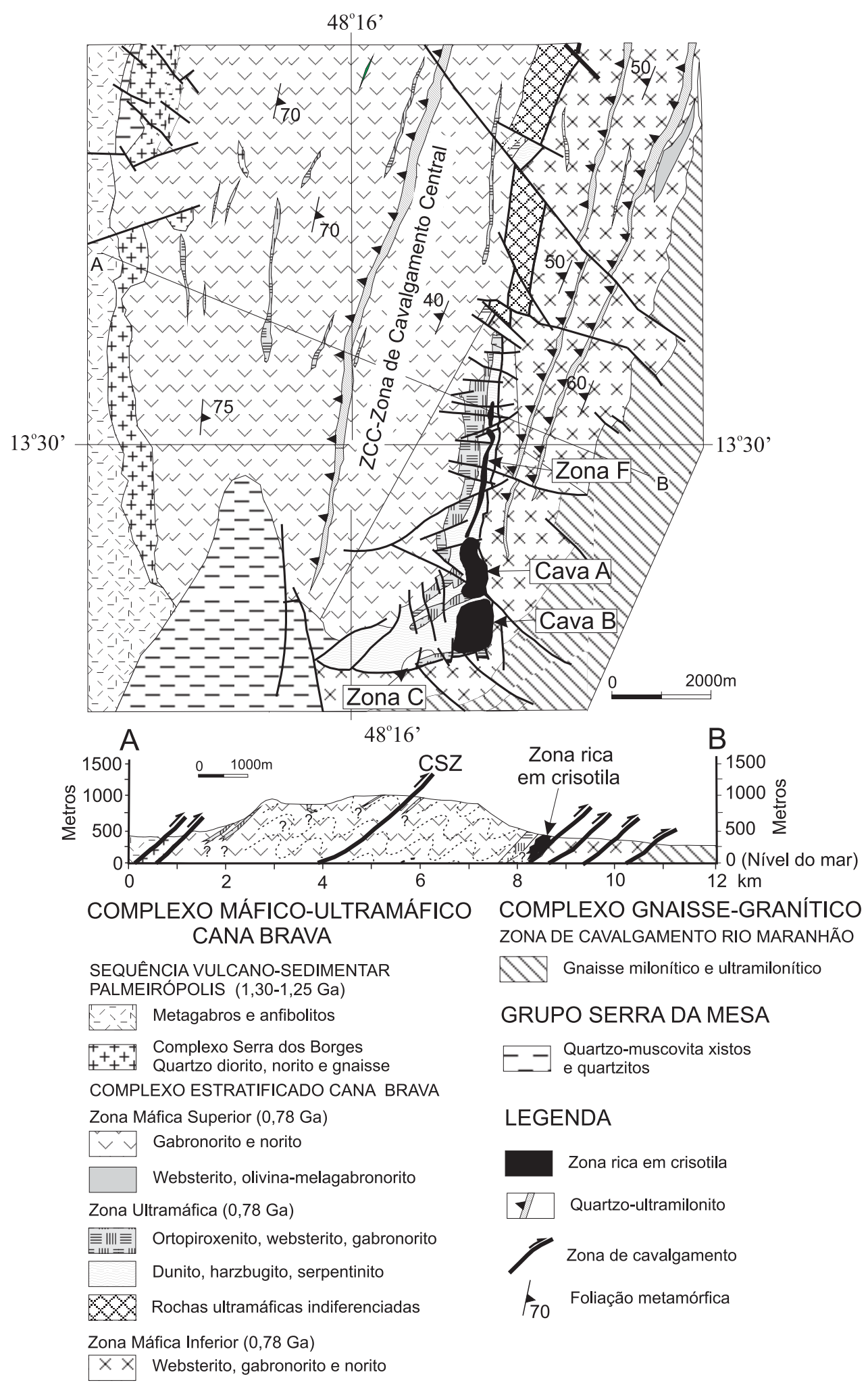

Figura 3. Geologia da parte sul do Complexo Cana Brava. Notar a localização das zonas C e F, mineralizadas em crisotila, e das cavas A e B da mina Cana Brava. Notar, também, que o Complexo Estratificado, situado na base do complexo, é a unidade mais jovem do complexo. 
A Zona Ultramáfica contém metaperidotito na base e piroxenito, sobretudo websterito, às vezes feldspático ou pegmatoide, no topo. Localmente foram identificados dunitos com cromo-espinélio disseminado. Rochas ultrabásicas serpentinizadas dessa zona hospedam o minério de crisotila lavrado nas cavas A e B da mina Cana Brava (Figura 3).

\section{G eologia estrutural}

As principais feições deformacionais do Complexo pertencem a um evento dúctil (Dn), associado ao primeiro episódio metamórfico que gerou uma foliação plano-axial Sn de direção $\mathrm{N} 00^{\circ}-30^{\circ} \mathrm{E}$ e caimentos convergentes em direção a região axial do complexo, marcada pela presença de uma grande falha, com ultramilonitos, denominada zona de cisalhamento central (Lima, 1997). Este evento promoveu uma reorientação dos acamamentos ígneos, os quais se (sub) paralelizaram a foliação Sn. Associado ao evento de deformação dúctil (Dn) desenvolveu-se no Complexo de Cana Brava um metamorfismo da fácies granulito. A foliação metamórfica associou-se ao desenvolvimento de grandes ondulações sinformais e antiformais e, por último, transcorrências dúcteis e rúpteis que, na área da mina, apresentam direção NE-SW e deslocamento dextral.

Zonas de cisalhamento de alto "strain", com direção (sub) paralela a foliação Sn, são encontradas intercaladas nos granulitos máficos. São compostas principalmente por ultramilonitos ricos em quartzo, localmente bordejados por anfibolitos. A oeste, o contato entre os anfibolitos metavulcânicos e os noritos e quartzo-noritos é uma falha reversa oblíqua, com movimentação sinistral. A leste, no domínio da Zona Máfica Inferior há, também, duas zonas de falha com ultramilonitos, semelhante a CSZ (Figura 3), e que aparentemente possuem a mesma movimentação destral da zona de falha na base do complexo.

A estrutura geral do complexo assemelha-se àquelas dos modelos de zona de cisalhamento em flor positiva (Lima, 1997). Um evento rúptil tardio manifesta-se por fraturas/falhas com direções preferenciais entre N40-60W, na base do complexo, e N40-50E no topo. Essas fraturas segmentaram os corpos mineralizados e deslocaram blocos em ambiente distensional. A parte superior do complexo foi segmentada por uma zona de cisalhamento horizontal que atingiu todos os corpos mineralizados.

\section{O s corpos mineralizados e suas estruturas}

A região mineralizada em crisotila situa-se no extremo sul do Complexo Cana Brava (Figura 3). A mineralização em crisotila foi consequência de um tectonismo ocorrido após a colisão entre os páleo-continentes São Francisco e Amazonas, há 0,63 Ga, o que causou metassomatismo e o hidrotermalismo que serpentinizaram as rochas ultrabásicas e geraram o minério com crisotila. A região mineralizada é composta pelas zonas mineralizadas $\mathrm{A}, \mathrm{B}, \mathrm{C}$ e $\mathrm{F}$, interligadas, que formam um corpo mineralizado único, com cerca de 4,5 km de extensão e 0,2 a 1,0 km de largura, orientado N-S (Figura 4A). Toda a região mineralizada foi modelada tridimensionalmente com informações de 869 sondagens verticais feitas entre 1966 e 2009, com comprimentos entre 50 e $250 \mathrm{~m}$, executadas segundo em uma malha regular triangular de $35 \times 35 \mathrm{~m}$, orientada NW. Desde 1966 as zonas mineralizadas A e B têm sido lavradas nas cavas A e B, respectivamente (Figuras 4B e C), e as zonas $\mathrm{C}$ e F são conhecidas apenas em sondagens.

As fraturas mapeadas nas cavas foram modeladas e inseridas no modelo geométrico, o que permitiu dividir o corpo mineralizado em 13 blocos (Figura 5). Todas as fraturas seccionam a zona de cisalhamento sub-horizontal que atingiu a parte superior da zona mineralizada (Figura 5).

\section{Determinação dos elipsoides de anisotropia dos blocos}

Para a construção dos elipsoides de anisotropia variográfica dos 13 blocos de minério foi necessário individualizar a população de sondagens contida em cada um dos blocos, como exemplificado na Figura 6 (correspondente ao bloco 7 da Figura 5). Isso foi feito restringindo-se as sondagens aos chamados "objetos" ou blocos, o que gerou 13 conjuntos independentes de teores de crisotila.

O estudo estatístico, em cada bloco, da variável teor total de crisotila (MbTT), mostrou que essa variável apresenta uma distribuição log-normal. As amostras contidas em cada bloco foram regularizadas com uma tolerância de $10 \%$, em intervalos de 13 em 13 m, correspondentes a altura média das bancadas da mina Cana Brava. Os valores regularizados foram utilizados para calcular variogramas em cada bloco, como os calculados, p.ex., para o bloco 1 (Figura 7). Os variogramas utilizados para construir o elipsoide de anisotropia de cada bloco foram calculados com auxílio da ferramenta "mapa variográfico" de um "software" de modelagem geoestatística, que permite gerar variogramas simultaneamente em até 36 direções, correlacionando-os em um mapa de variâncias. Determinados os elipsoides de anisotropia de cada bloco, os blocos cujos elipsoides apresentaram-se com eixos paralelos foram agrupados, gerando 6 grandes blocos (Tabela 1 e Figura 8).

\section{Estudo cinemático comparativo}

Com a ferramenta "mapa de variográfico" foi possível determinar o mergulho (dip), a direção (dip direction) e as dimensões (A1 = maior alcance) dos três eixos 


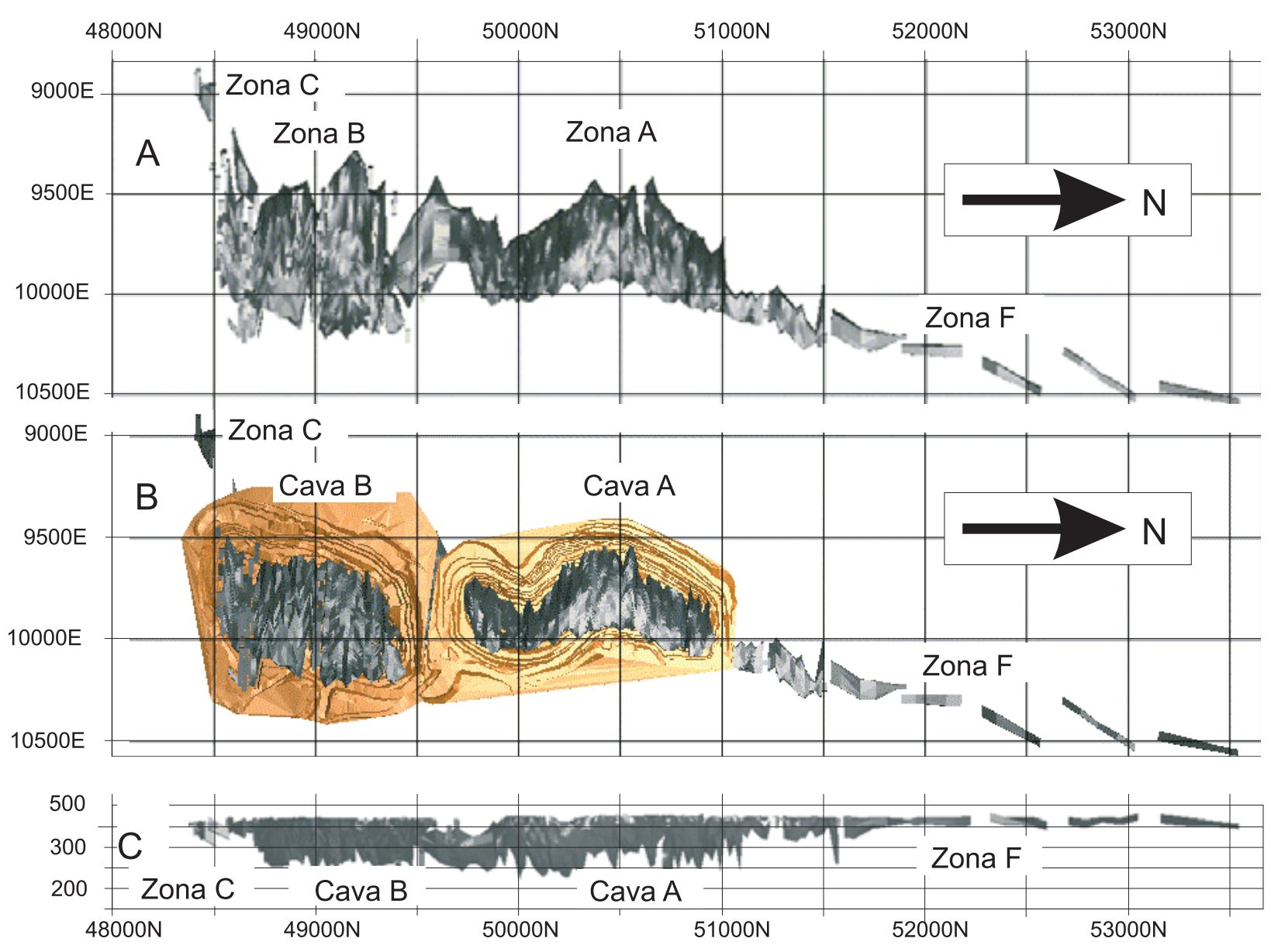

Figura 4. Projeções dos modelos geométricos das zonas mineralizadas A, B, C e F do depósito de crisotila Cana Brava: A. em plano horizontal; B. em plano horizontal junto com as cavas A e B; C. em plano vertical.

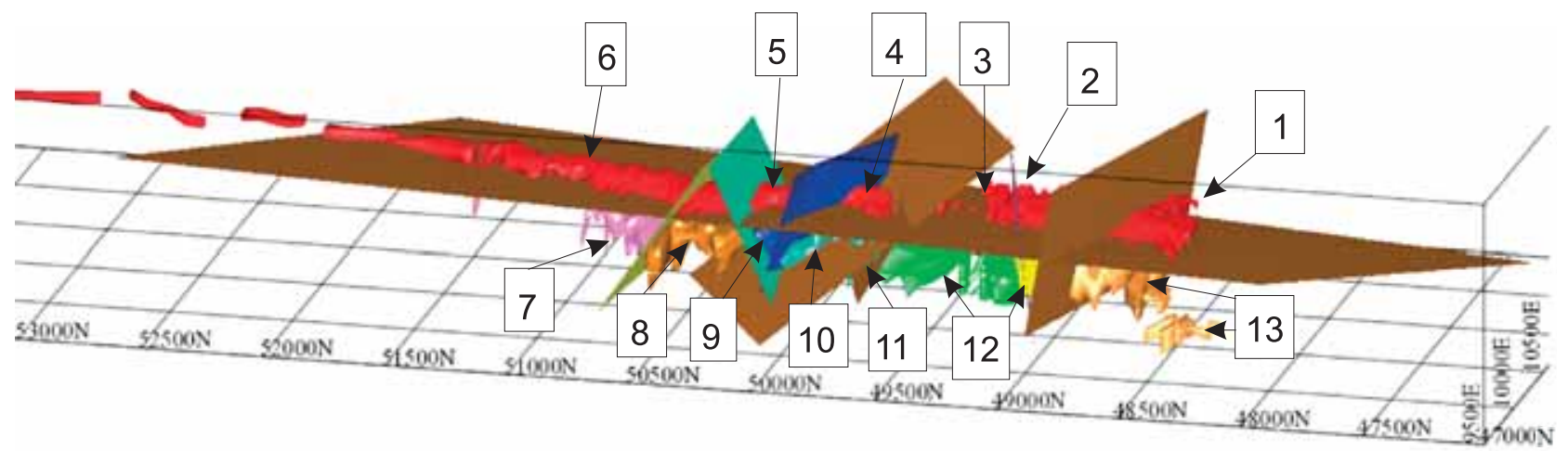

Figura 5. Modelo geométrico da zona mineralizada do depósito de crisotila Cana Brava, realçando as fraturas que a seccionam e a dividem em 13 blocos. Notar a zona de cisalhamento sub-horizontal que secciona o topo da zona mineralizada e é seccionada por todas as outras fraturas. As características dos elipsoides de anisotropia de cada um dos 13 blocos constam na Tabela 1, nas 3 últimas colunas, no lado direito. 


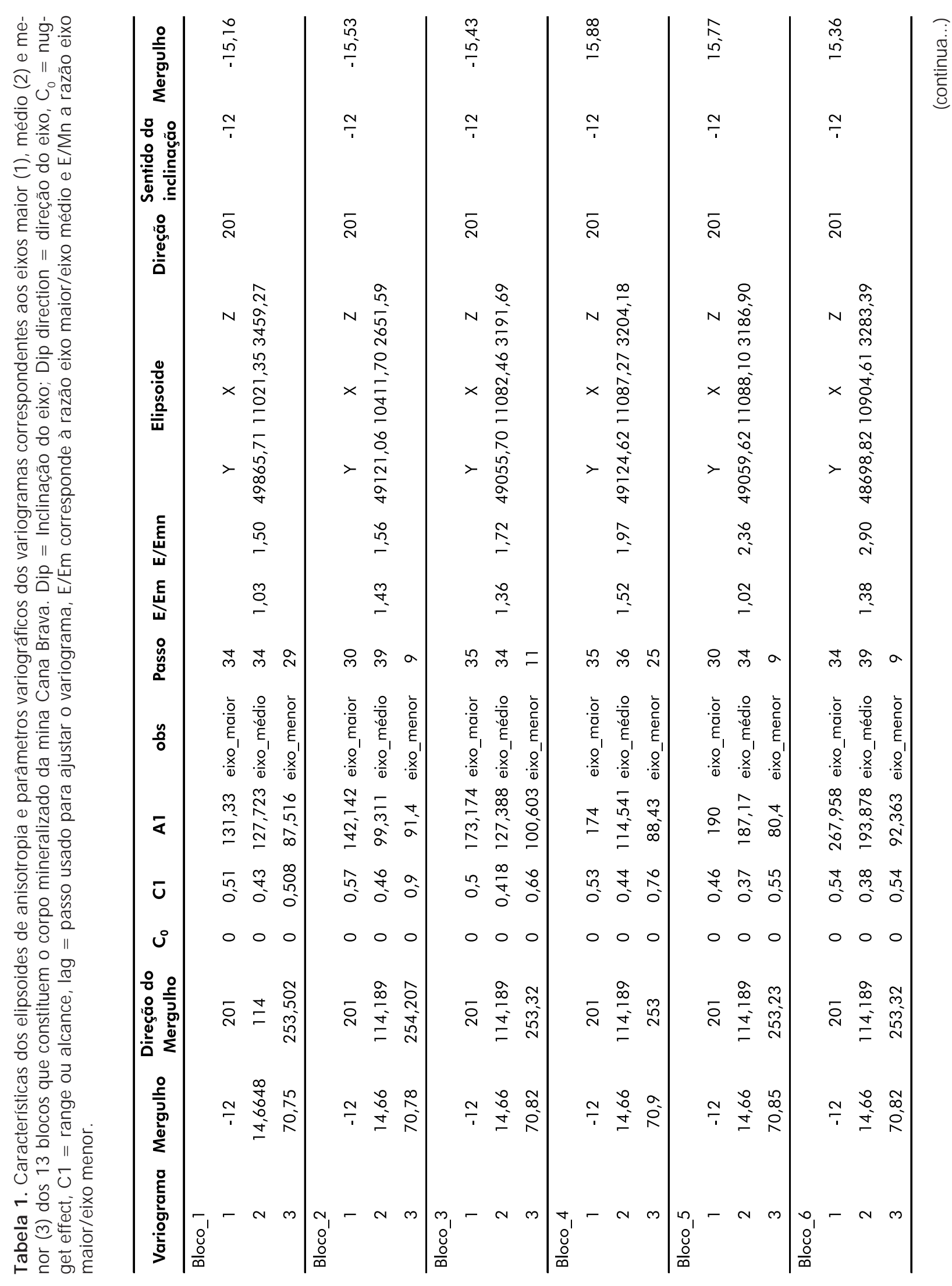




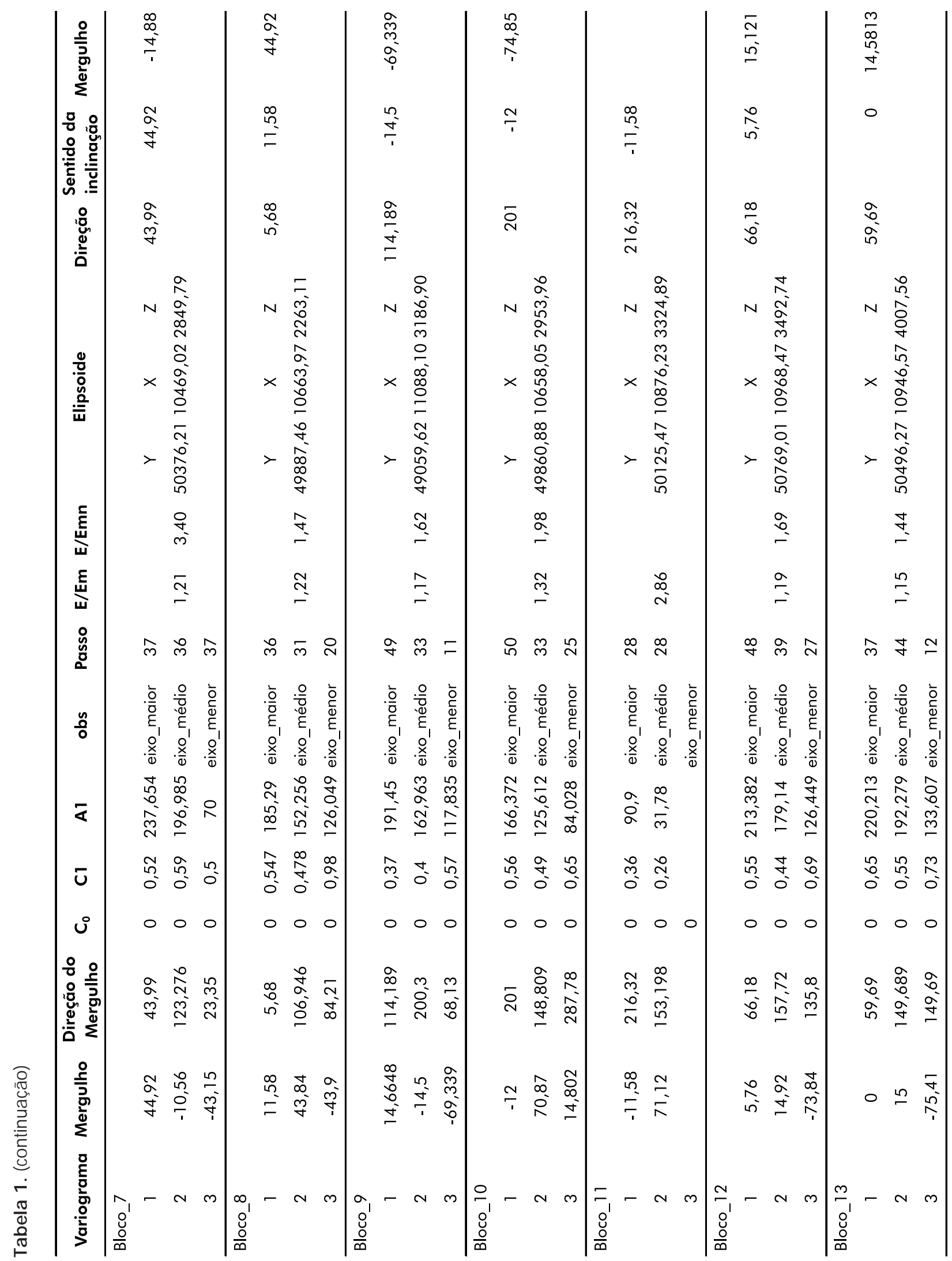




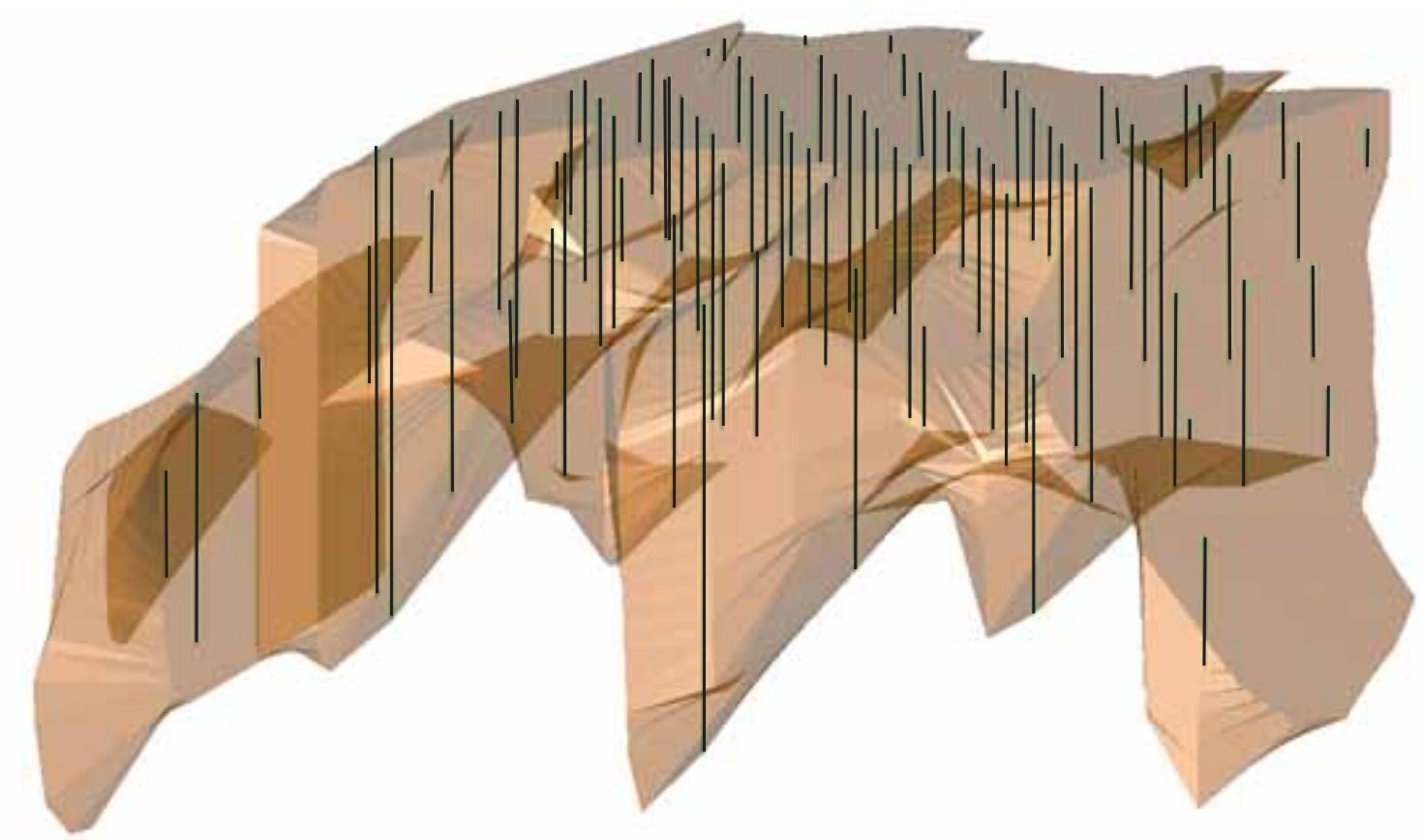

Figura 6. Imagem do bloco ou "objeto" no 8 (ver Figura 5), com efeito de transparência, o que permite visualizar as sondagens contidas no objeto, ou "restritas" ao objeto.

de anisotropia variográfica (eixo maior, médio e menor) e construir os elipsoides de anisotropia de cada um dos 13 blocos (Figura 5 e Tabela 1). Dessas variáveis, o mergulho e a direção dos eixos dos elipsoides de anisotropia indicam melhor a rotação dos blocos que a dimensão dos eixos (alcance), dado que essa última variável é sensível a todos os fatores que causam variação do teor de crisotila, sobretudo as recristalizações, tão comuns em ambientes hidrotermais relacionados à fraturamento intenso, como foi o caso em Cana Brava. Tendo isso em consideração, foram unidos os blocos que, na Tabela 1 (três últimas colunas a direita), apresentam elipsoides de anisotropia cujos eixos são paralelos ou com mergulhos e direções semelhantes. No caso de existência de rotação entre os blocos, os eixos dos elipsoides não devem coincidir, pois a cinemática das falhas muda a direção dos eixos dos elipsoides dos blocos rotados, o que truncaria a continuidade da variável. No caso dos eixos dos elipsoides de anisotropia possuírem orientações semelhantes, pode-se admitir que a falha não rotou o bloco ou sua movimentação foi tão tênue que não modificou a atitude original do bloco.

Blocos cujos elipsoides possuem orientação espacial semelhantes (Tabela 1) foram considerados não rotados e agrupados, o que reduziu o número de blocos, ou "objetos", de 13 para 6, mostrados nas Figuras 8A e B. Esses blocos correspondem a 6 diferentes direções de continuidade da variável Mb_TT, teor total acumulado de crisotila, em cada bloco.

\section{Estimativa dos recursos minerais originais contidos no depósito de crisotila Cana Brava}

O variograma de maior alcance de cada um dos seis blocos, e os respectivos elipsoides de anisotropia, foram utilizados para estimar, com krigagem ordinária, a quantidade de minério contido no depósito Cana Brava em 1966, quando começou a ser lavrado. Os resultados são apresentados na Figura 9, em uma curva de parametrização teor de corte $v s$. tonelagem de minério.

A SAMA testou as estimativas feitas comparando os teores reais de crisotila de blocos lavrados com os teores estimados para os mesmos blocos. Segundo informações da Empresa, foram encontradas variações de teores de $\pm 2 \%$ em peso para blocos lavrados cujos centroides estão contidos no interior do modelo geométrico do corpo mineralizado (Figura 5). Blocos lavrados cujos centroides estão fora desse modelo apresentaram diferenças entre os teores lavrados e os estimados de $\pm 50 \%$. 

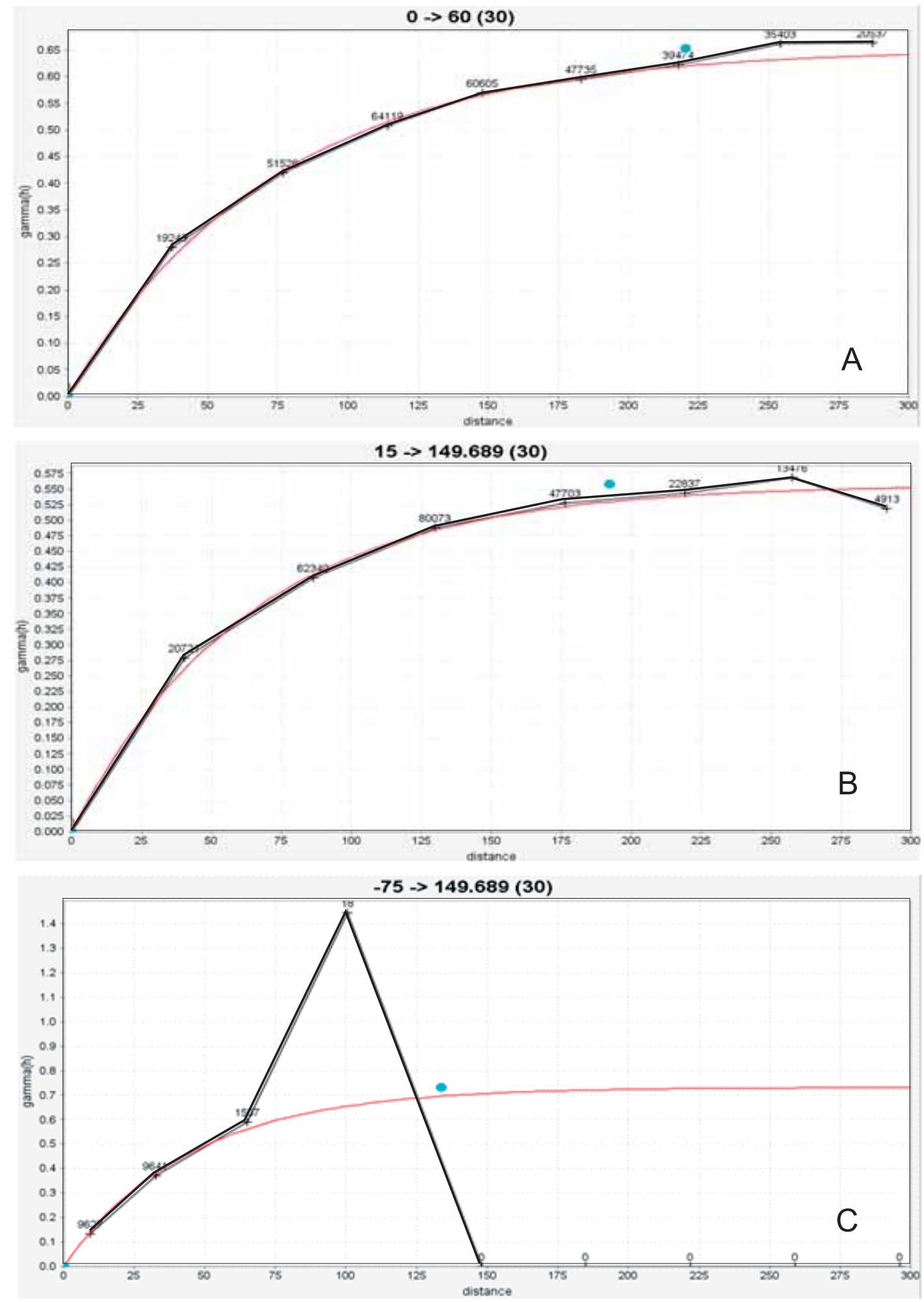

Figura 7. Exemplos de variogramas (experimentais e modelados) calculados com a ferramenta "mapa variográfico" para o bloco 1. A. Variograma do eixo maior; B. do eixo médio; C. do eixo menor, do elipsoide de anisotropia da variável Mb_T do bloco 1 . O s parâmetros dos variogramas dos elipsoides de anisotropia dos 13 blocos que constituem o corpo mineralizado de Cana Brava são mostrados na Tabela 1. 

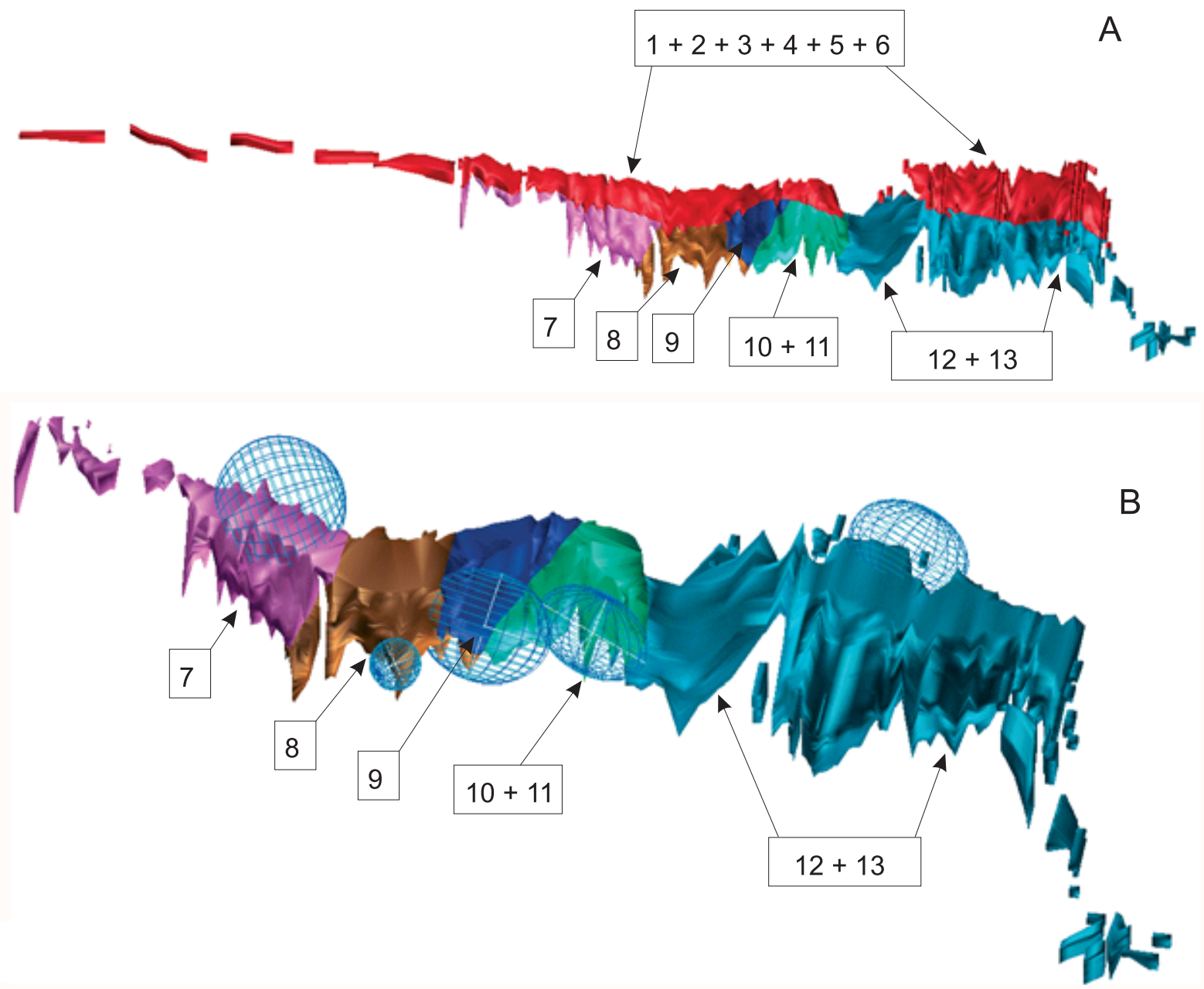

Figura 8. A. Resultado do agrupamento dos blocos que possuem elipsoides de anisotropia com a mesma orientação espacial (comparar com a Figura 5). O s 13 blocos individualizados por fraturas (Figura 5) foram agrupados em 6 blocos maiores, cujos elipsoides possuem a mesma orientação espacial. Notar que a parte do corpo mineralizado situada acima da zona de cisalhamento sub-horizontal que secciona o topo do corpo mineralizado agora constitui um único bloco. B. Novos elipsoides de anisotropia de blocos mostrados na Figura 8A. 0 bloco superior, situado acima da zona de cisaIhamento sub-horizontal, não é mostrado nessa figura.

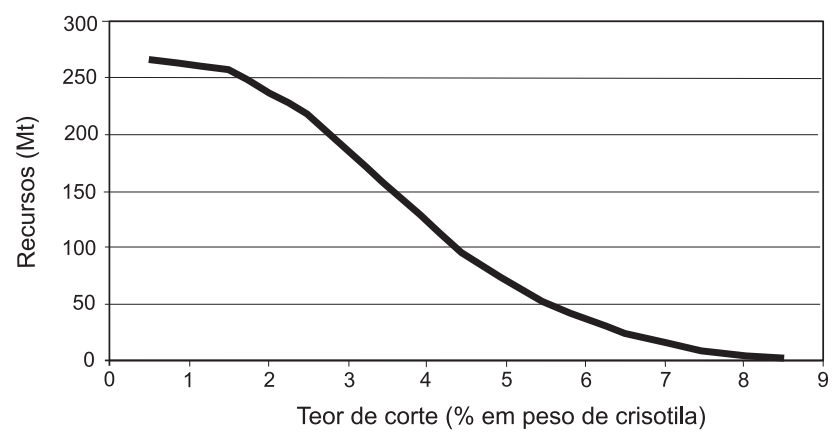

Figura 9. Curva de parametrização dos recursos contidos no depósito de crisotila Cana Brava antes do início da lavra (recursos originais, em 1966). 


\section{REFERÊNCIAS}

CORREIA, C. T.; GIRARDI, V. A. V.; TASSINARI, C. C. G.; JOST, H. Rb-Sr and Sm-Nd geochronology of the Cana Brava layered mafic-utramafic intrusion, Brazil, and considerations regarding its tectonic evolution. Revista Brasileira de Geociências, v. 27, n. 2, p. 163-168, 1997.

FERREIRA FILHO, C. F.; KAMO, S.; FUCK, R. A.; KROGH, T. E.; NALDRETT, A. J. Zircon and rutile geochronology of the Niquelândia layered mafic and ultramafic intrusion, Brazil: constraints for the timing of magmatism and high grade metamorphism. Precambrian research, v. 68, p. 241-255, 1994.

FERREIRA FILHO, C. F.; MORAES, R.; FAWCET, J. J.; NALDRETT, A. J. Amphibolite to granulite progressive metamorphism in the Niquelândia Complex, central Brazil: regional tectonic implications. Journal of South American Earth Sciences, v. 11, n. 1, p. 35-50, 1998.

FERREIRA FILHO, C. F.; PIMENTEL, M. M. Sm-Nd isotope systematics and REE-Hf-Ta-Th data of troctolites and their amphibolitized equivalents of the Niquelândia Complex Upper Layered Series, central Brazil: further constraints for the timing of magmatism and highgrade metamorphism. Journal of South American Earth Sciences, v. 13, n. 7, p. 647-659, 2000.

FERREIRA FILHO, C. F.; PIMENTEL, M. M.; ARAUJO, S. M.; LAUX, J. H. Layered intrusions and volcanic sequences in Central Brazil: Geological and Geochronological constraints for Mesoproterozoic (1.25 $\mathrm{Ga})$ and Neoproterozoic (0.79 Ga) igneous associations. Precambrian Research, v.183, n. 3, p. 617-634, 2010.

LIMA, T. M. Geologia, Estratigrafia e Petrologia da Porção Sul do Complexo Máfico-Ultramáfico de Cana Brava, Goiás. 1997. 300 f. Dissertação (Mestrado) Instituto de Geociências, Universidade de Brasília, Brasília (DF), 1997.

PIMENTEL, M. M.; ARMSTRONG, R. A.; FERREIRA FILHO, C. F. SHRIMP U-Pb and Sm-Nd ages of the Niquelândia Layered complex: Meso (1.25 Ga) and Neoproterozoic $(0.80 \mathrm{Ga})$ extensional events in Central Brazil. In: SOUTH AMERICAN SYMPOSIUM ON ISOTOPE GEOLOGY, 4., 2003, Salvador. Short Papers... Salvador: CBPM/IRD, 2003. p. 639-642.

SANTOS, C. E. Modelo Geoestatístico e Geológico do Depósito de Crisotila da Mina Cana Brava (Minaçu, GO).
2011. 157 f. Dissertação (Mestrado) - Depto de Geologia, Universidade Federal do Paraná, Curitiba, 2011. 